Clinical and

\section{morphological features of Waardenburg syndrome type II}

PAUL B. MULLANEY,

M. ANDREW PARSONS,

ROBERT G. WEATHERHEAD,

ZEYNEL A. KARCIOGLU

\section{Abstract}

Evaluation of 4-month-old girl who presented with congenital cataracts revealed

heterochromia iridis, fundus

hypopigmentation, residual white forelock and sensory neural hearing loss - findings consistent with Waardenburg syndrome type II. Bilateral peripheral iridectomies performed at lensectomy provided tissue for evaluation. Light microscopy revealed fewer melanocytes in the blue iris than in the brown. Electron microscopic examination showed a significant $(p=0.0001)$ reduction in melanosome size in the blue iris, and the nerve endings contained fewer vesicles. A defect in neural crest cell migration and melanin synthesis may be responsible for the heterochromia iridis seen in Waardenburg syndrome type II.

Key words Heterochromia, Iris, Iris colour, Melanocyte, Waardenburg syndrome

In 1951 Waardenburg described a syndrome combining congenital deafness, medial canthal dystopia, synophrys, and broadening of the nasal root with pigmentary disorders of the irides, skin and head hair. ${ }^{1}$ Waardenburg syndrome (WS) was subsequently divided into types I and II based on the presence or absence respectively of dystopia canthorum. ${ }^{2,3}$ Further heterogeneity in this syndrome was evidenced by reports of its existence with ocular albinism, Hirschsprung megacolon, and Marcus Gunn ptosis. ${ }^{4,5}$ Waardenburg syndrome type II is an autosomal dominant disorder that has been linked to a mutation in the mitf gene on chromosome three. ${ }^{6}$

In addition to Waardenburg's original ocular findings, Goldberg ${ }^{7}$ described anomalies of fundus coloration that paralleled those of the iris. We report a 4-month-old infant who presented with bilateral congenital cataracts coincident with stigmata of WS. Bilateral consecutive lens aspiration enabled peripheral iridectomy specimens to be obtained and studied by light and electron microscopy.

\section{Case report}

A 4-month-old Saudi girl presented with nystagmus of 2 months' duration, and more recently bilateral leucocoria. Her fixation was non-central, non-steady and non-maintained in both eyes. The conjunctiva, cornea and anterior chamber were within normal limits. The right iris and lower half of the left iris were blue; the upper half of the left iris was brown (Fig. 1). The pupils were round, equal, and reacted symmetrically in both a normal and a poorly illuminated environment. Bilateral central nuclear lens opacities were present. A number of white hairs were present in the anterior part of the scalp. The mother reported there had been many more shortly after birth but their number was diminishing.

Brain stem auditory-evoked responses in the right ear revealed a threshold between 60 and 80 decibels $(\mathrm{dB})$. At $95 \mathrm{~dB}$ all waves were delayed and small in amplitude with delayed interwave latencies. This result was consistent with severe sensory neural hearing loss. The left ear was not as badly affected, with a hearing threshold of 40-60 dB and delay at $95 \mathrm{~dB}$ of all waves and interwave latencies. Urinary vanillylmandelic acid levels were normal, as was the chest radiograph.

As the parents were unwilling to bring other family members for examination it was not possible to determine the inheritance pattern. However, a 3-year-old male sibling was reported to have had a white frontal blaze at birth that disappeared. The father's brother had a similar history. No deafness was reported in the family and the medical history was otherwise non-contributory for stigmata of WS.

The child was examined under anaesthesia. Measurements of the inner intercanthal distance, the interpupillary distance and the outer intercanthal distance were obtained. Slitlamp examination of the blue irides revealed hypoplastic stroma in addition to hypopigmentation. As a result, the iris vasculature was visible in all areas of hypoplastic stroma. Fundus hypopigmentation paralleled that found in the irides of both eyes (Fig. 2). Bilateral consecutive lensectomies and peripheral iridectomies were performed on

\author{
P.B. Mullaney \\ R.G. Weatherhead \\ Z.A. Karcioglu \\ King Khaled Eye Specialist \\ Hospital \\ Riyadh \\ Saudi Arabia \\ Z.A. Karcioglu \\ Department of \\ Ophthalmology \\ Tulane University Medical \\ School \\ 1430 Tulane Ave \\ Room 5020 \\ New Orleans \\ LA 70112, USA \\ Fax: +1(504) 5842684 \\ M.A. Parsons \\ Ophthalmic Sciences Unit \\ University of Sheffield \\ Sheffield, UK
}




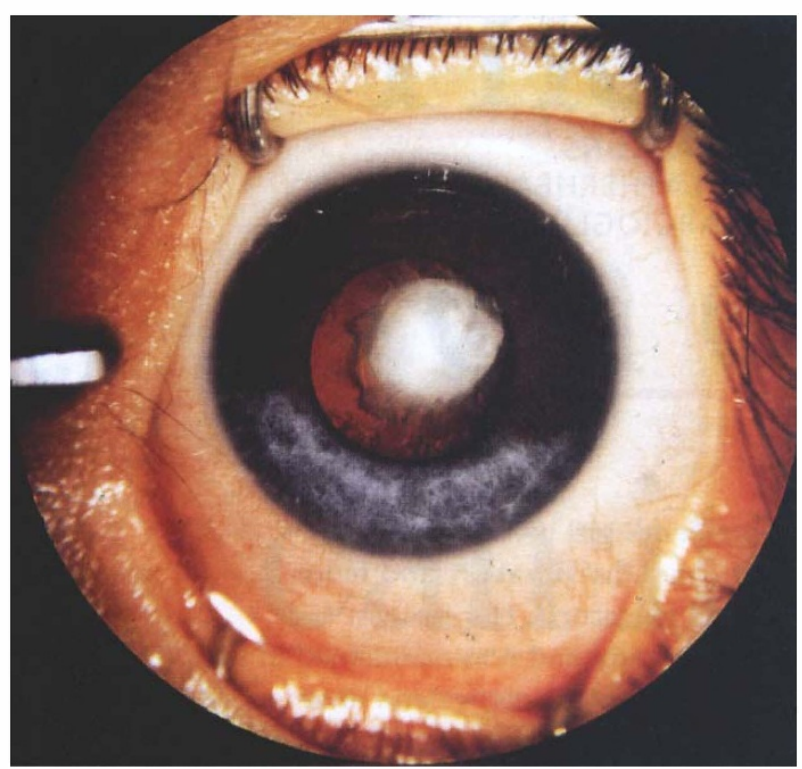

Fig. 1. Patient's left bicoloured iris with congenital cataract.

separate surgical days. A segment of blue iris was retrieved from the right, and a normal-appearing brown specimen from the left. The post-operative course was uneventful. The child was fitted with contact lenses.

The iris specimens were processed for light and electron microscopy. Those for light microscopy were stained with haematoxylin-eosin and methylene blue. Specimens for transmission electron microscopy were fixed in $2.6 \%$ glutaraldehyde buffered to $\mathrm{pH} 7.4$ with $0.1 \mathrm{M}$ Sorensen phosphate buffer. Post-fixation followed in $1 \%$ osmium tetroxide buffered with $0.1 \mathrm{M}$ Sorensen phosphate buffer. Specimens were then dehydrated in graded alcohols and embedded in Araldite epoxy resin. The Reichert Ultracut E ultramicrotome was used to section the specimens, which were then examined with a Philips 420 electron microscope.

For morphometric studies, six electron micrographs from both blue and brown areas of original magnification

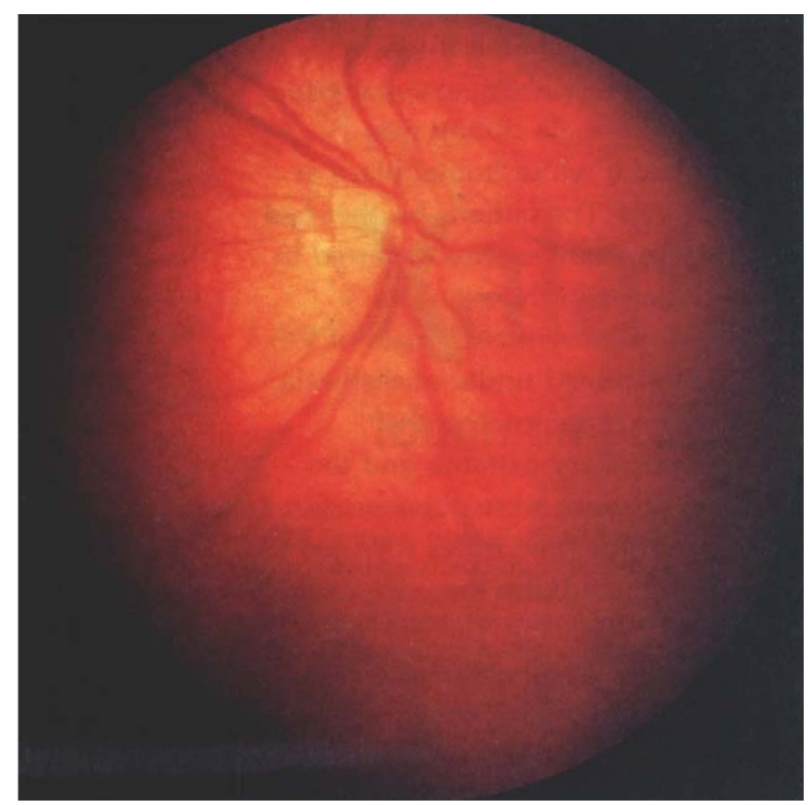

Fig. 2. Left fundus hypopigmentation.
48000 were enlarged to give photographic prints with a final magnification of 13900 . The longest axis of each melanosome was measured manually by a quantitative method used for melanosomes in cultured melanocytes. ${ }^{8}$ All the melanosomes in photomicrographs from blue areas $(n=47)$ and brown areas $(n=1563)$ were measured, and comparisons between these sizes were determined using Welch's correction to the (alternate) $t$-test; results were expressed as the mean value \pm SEM. Differences in the proportion of melanocytes above and below $290 \mathrm{~nm}$ in their longest axis were assessed using Fisher's Exact Test. Melanocytes were defined by the presence of melanosomes only. The total areas of melanocyte cytoplasm sampled in blue and brown areas were derived from the weight of cytoplasmic areas cut out (manually) from the electron photomicrographic print of known size and weight. Density of melanosomes per unit area of cytoplasm $\left(\mu \mathrm{m}^{2}\right)$ was calculated using the known total number of melanosomes in blue and brown areas. Melanosome sizes were expressed in nanometres, but measured in millimetres (range 1-14) on electron micrographs at final magnification. A comparison of iris neuronal terminals in corresponding blue and brown areas was also performed, by contrasting the respective electron micrographs. However, this comparison was not subject to rigorous qualification or quantitation.

\section{Results}

The inner intercanthal distance was $23 \mathrm{~mm}(a)$, the interpupillary distance was $42 \mathrm{~mm}(b)$ and the outer intercanthal distance was $71 \mathrm{~mm}(c)$. We used dystopia indices for WS as reported by Arias ${ }^{2}$ where: $L=a-$ $0.2497, b-0.2119, c-3.909=6.4413 ; X=[2 a-(0.2119 c$ $+3.909)] / c=0.3809 ; Y=[2 a-(0.2497 b+3.909)] / b=$ 0.7525 . The normal range for $a / b$ is $0.50-0.55$. ${ }^{9}$ The $a / b$ value for our patient was 0.5476 . The $W$ index for this child [where $W=X+Y+(a / b)$ ] was 1.681 , indicating that she did not have dystopia canthorum. This was consistent with the clinical picture of WS type II.

As previously described, the predominant cell population of the iris stroma included melanocytes and fibroblasts in the iris tissue samples from both blue and brown areas. ${ }^{10}$ Light microscopic examination of plasticembedded, thick sections revealed many more

pigmented melanocytes in the stroma of the brown areas. The blue iris stroma contained fewer pigmented melanocytes and overall it was thinner than the brown iris. The pigment distribution was denser towards the anterior surface of the stroma.

Electron microscopic examination revealed a much smaller total number of melanosomes $(n=47)$ in blue areas of the iris than in brown areas $(n=1563)$. In brown areas the melanosomes were significantly larger than in blue areas, with a wider size distribution (Fig. 3); there was also a significantly increased density of melanosomes (Table 1).

Neuronal terminals were located close to the cytoplasmic membranes of the fibroblasts or melanocytes and contained numerous circular or oval vesicles 

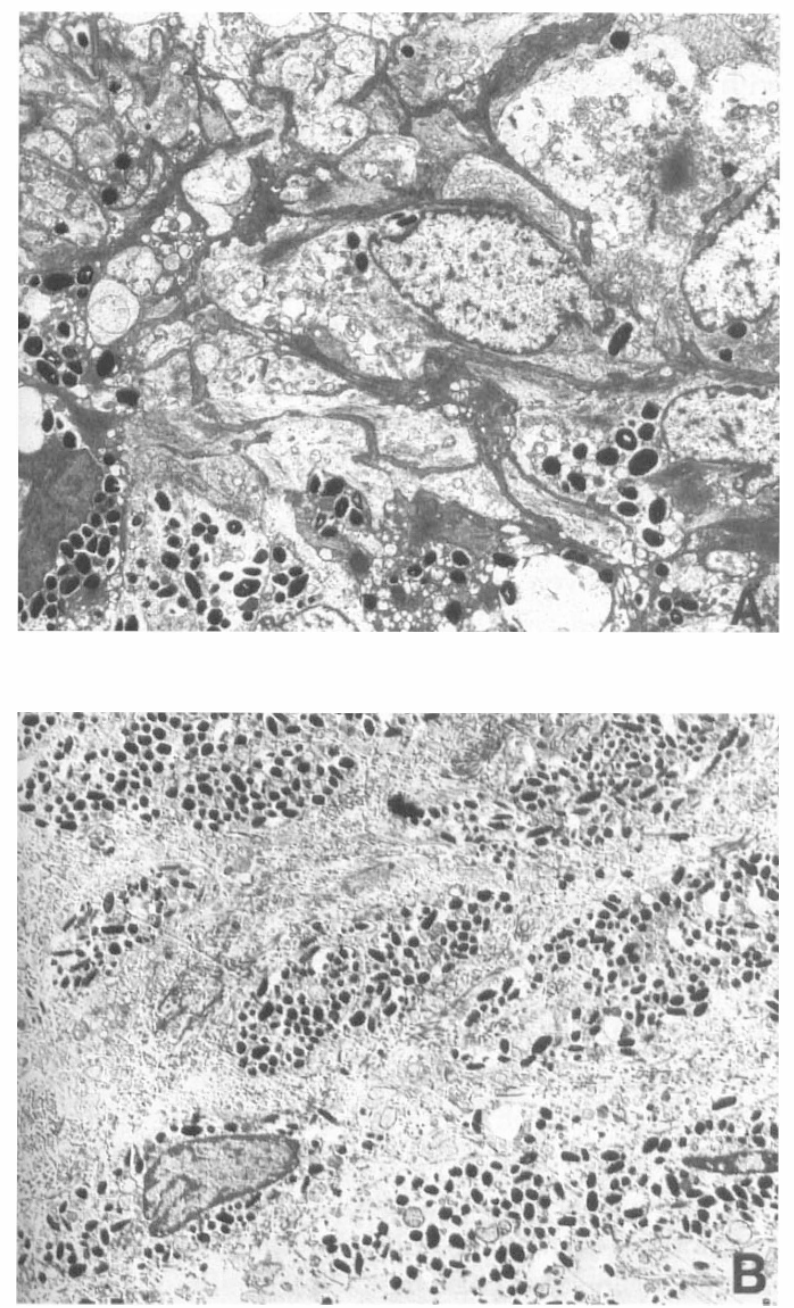

Fig. 3. Transmission electron micrographs depicting the numerical and structural differences of melanosomes between $(A)$ blue and $(B)$ brown irides (original magnification 5300).

intermingled with mitochondria. In both blue and brown samples most vesicles were translucent, measuring 25-100 nm in diameter, with only a few dense-cored vesicles being identified (Fig. 4A, B). Vesicle size did not vary between brown and blue areas. Numerous nerve terminals adjacent to melanocytes were identified in the brown areas and contained many round and ovoid vesicles. In blue areas the numbers of vesicles varied, some areas being packed with translucent vesicles similar to brown areas while other areas totally lacked them. Although no quantification could be done, in general the nerve endings in the blue iris contained fewer vesicles than the nerve endings of the brown iris (Fig. 4A, $B$ inserts). Occasional dense-cored larger vesicles were present in blue areas.

\section{Comment}

The diagnosis of WS can be difficult because of the broad range of presenting signs. This is particularly applicable in WS type II where dystopia canthorum is not present. Others state that a minimum of three positive findings should be present to make the diagnosis. ${ }^{11}$ A recent review by Liu et al. ${ }^{12}$ reported that hearing loss, heterochromia and absence of dystopia canthorum are the most important findings in WS type II. Our patient had a residual white forelock with bicoloured irides, sensory neural hearing loss, fundus hypopigmentation and absence of dystopia canthorum. The presence of congenital cataracts in our patient appears to be coincidental; however, bilateral anterior axial embryonal cataracts have been recorded although not apparently visually significant. ${ }^{7}$

African patients more frequently manifest pigmentary disorders and deafness without dystopia (WS type II) than Caucasians. ${ }^{13}$ A review of WS in South Africa showed that in the absence of deafness, patients with WS type II may remain undetected. Many of these patients manifest only iris heterochromia and a white forelock. ${ }^{14}$ Marked heterogeneity in WS has been reported by Bard et al.; ${ }^{4}$ in one large family in their study some members manifested heterochromia, and fundus hypopigmentation without synophrys, dystopia or deafness, while other members had the full syndrome inclusive of deafness. Feingold et al. ${ }^{15}$ reported that a child with iris bicolor and an early white forelock had a sibling with WS associated with profound deafness.

The fact that signs associated with WS change with increasing age complicates the diagnosis. Progressive colour changes in hair and iris in patients with WS in the first year of life have been described. ${ }^{13}$ Our patient's white forelock may disappear and pigmentation of the iris may continue.

Controversy exists as to determinants of iris colour. A recent report suggests that it is related to size and number of melanosomes in superficial melanocytes. ${ }^{16}$ Others contend that iris colour is independent of melanocyte number. ${ }^{17,18}$ However, some investigators attribute iris colour to variations in melanocyte number. ${ }^{19}$ On our evaluation, a significant difference in melanosome size and number was evident between the blue and brown iris. By observation melanocytes appeared to be fewer in the blue iris. However, this could not be subjected to morphometric analysis because of sampling difficulties. Amelanotic melanosomes may have escaped detection as we did not perform immunoelectron microscopy.

Table 1. Comparison between melanosome sizes and density in blue and brown areas of heterochromic iris tissue

\begin{tabular}{lccc}
\hline Melanosome & Blue areas $(\mathrm{n}=47)$ & Brown areas $(\mathrm{n}=1563)$ & Statistical significance \\
\hline Mean size \pm SEM $(\mathrm{nm})$ & $216 \pm 11$ & $249 \pm \quad 3$ & $72-1008$ \\
Size range $(\mathrm{nm})$ & $144-432$ & $20.005^{\mathrm{a}}$ & - \\
Proportion of size $>290 \mathrm{~nm}$ & $6.4 \%$ & 4.04 & $p=0.015^{\mathrm{b}}$ \\
Density (number per $\mu \mathrm{m}^{2}$ ) & 0.26 & -
\end{tabular}

${ }^{a}$ Welch's alternate $t$-test.

bFisher's Exact Test. 

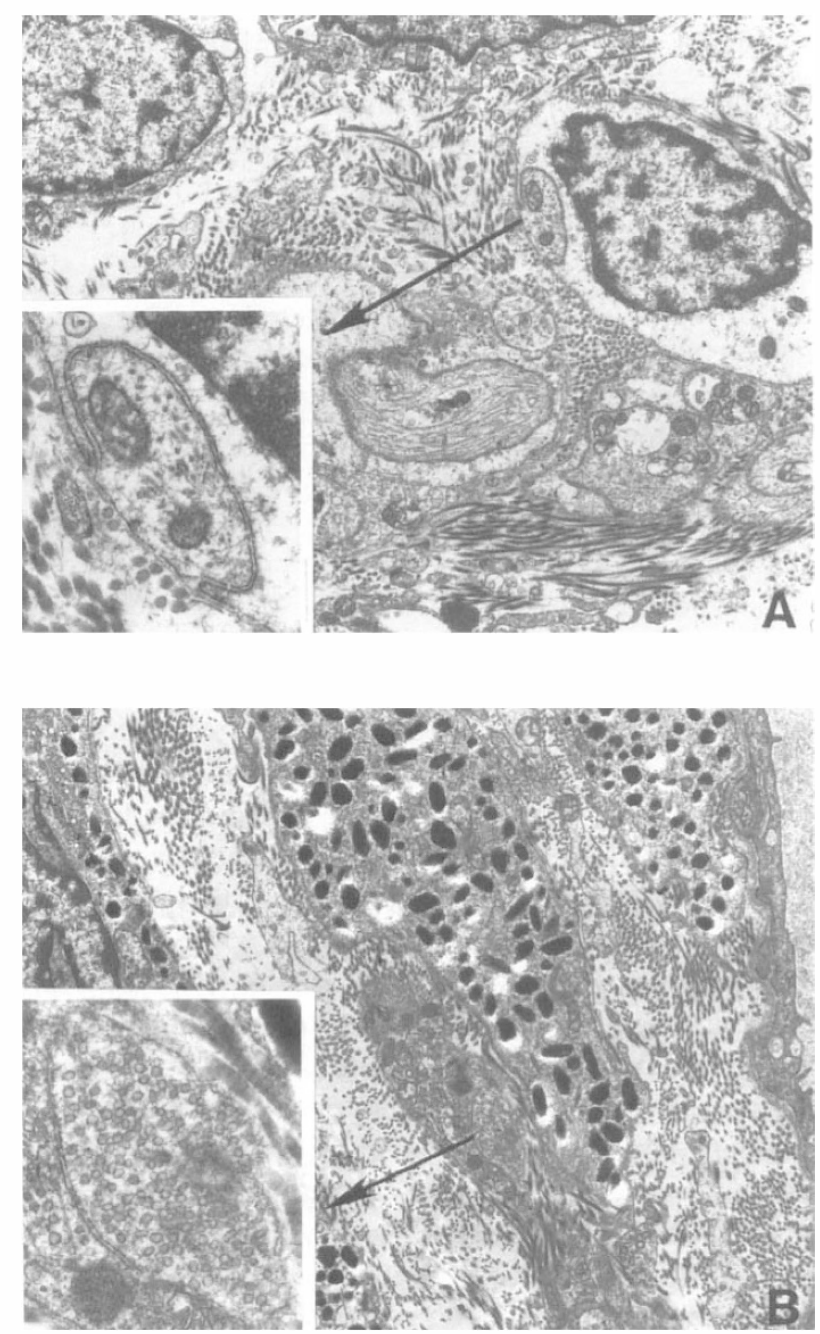

Fig. 4. (A) Transmission electron micrograph of the blue iris showing decreased number of vesicles in nerve endings (original magnification 8200; insert 11 000). (B) Transmission electron micrograph showing numerous vesicles within the nerve terminals relating to melanocytes and fibroblasts in the brown iris (original magnification 6350; insert 8500).

Iris heterochromia also occurs in congenital Horner syndrome. In Horner syndrome it is suggested that postganglionic lesions involving the cervical sympathetic chain interfere with melanocyte innervation. ${ }^{20}$ The ratelimiting enzyme in the synthesis of melanin from tyrosine is tyrosinase. Regulation of this enzyme is acutely sensitive to sympathetic innervation in certain cells. De-innervation of cervical sympathetics leads to a precipitous decline in tyrosinase activity. ${ }^{21,22}$

Melanocytes are found mainly in the anterior surface layer of the iris, where they are intimately associated with blood vessels and nerve fibres. ${ }^{19}$ In rat melanophores, adrenergic and cholinergic terminal axons are in close proximity. ${ }^{23,24}$ Although this relationship in humans is not clear, we have demonstrated many terminal axons in close proximity to melanocytes of the iris stroma in the normal control specimen used in this study (Fig. 4B). In lower animals, rapid colour changes are possible. ${ }^{25}$ Depigmentation seen in human irides after sympathectomy suggests the presence of a low-grade trophic mechanism. Indeed, it is felt that adrenergic terminals make the closest contact with melanocytes. ${ }^{26}$

A marked reduction in the number but not size of melanocytes in both the anterior border and stroma of the iris has been reported in a patient with Horner syndrome; an apparent lack of sympathetic axons was also noted in the affected iris. ${ }^{27}$ This suggests that in Horner syndrome postnatal maintenance of normal stromal and anterior border pigmentation is dependent upon an intact sympathetic nerve supply. In that patient, melanosome numbers did not vary greatly between the control and affected eye. In our patient, a reduced number of melanocytes containing small pigmented melanosomes were unequivocally present in the blue iris. This contrasted with the brown iris specimen where many highly pigmented melanosomes were present in numerous melanocytes.

Johnston et al. ${ }^{28}$ have suggested that neural crest cells have a crucial role in development of ocular and, in particular, anterior segment structures. Disorders of melanocyte development result from defects in neural crest lineages that include melanocytes and many other tissues. ${ }^{29}$ This is a conceivable explanation for the constellation of findings in our patient. Iris and choroidal pigment cells are thought to be of neural crest origin. Sensory neural hearing loss in WS is a result of absence of the organ of Corti and a reduction in the number of ganglion cells. ${ }^{30}$ This possibly is due to an abnormality in the proliferation of neural crest cells affecting melanosome-containing cells related to inner ear epithelia. ${ }^{31}$ In some patients, the association of iris bicolour with Hirschsprung megacolon also supports a common neural crest origin for these entities. ${ }^{5}$

In summary, we present a WS type II patient with a white forelock, sensory neural hearing loss, heterochromia iridis, choroidal depigmentation and congenital cataracts. Iris tissue obtained from peripheral iridectomy specimens was examined with light and electron microscopy. Reduced melanocyte numbers were seen in the blue iris; these cells contained sparse numbers of small melanosomes. In the contralateral brown iris, numerous melanocytes containing multiple melanosomes were present.

The authors extend thanks to Lynn C. Millar and Editha N. Cirujales for their assistance with morphological studies. We are grateful to Professor Ian R. Dunsmore of the School of Mathematics and Statistics, University of Sheffield, UK, for his advice on statistical analysis of melanosome data.

\section{References}

1. Waardenburg PJ. A new syndrome combining developmental anomalies of the eyelids, eyebrows, and nose root with pigmentary defects of the iris and head hair and with congenital deafness. Am J Hum Genet 1951;3:195-255.

2. Arias S. Genetic heterogeneity in the Waardenburg syndrome. Birth. Defects: Orig Art Ser 1971;7:87-101.

3. Arias S, Mota M. Apparent non-penetrance for dystopia in Waardenburg syndrome type I, with some hints on the diagnosis of dystopia canthorum. J Genet Hum 1978;26:103-31. 
4. Bard LA. Heterogeneity in Waardenburg syndrome: report of a family with ocular albinism. Arch Ophthalmol 1978;96:1193-8.

5. Meire F, Standaert L, De Laey JJ, Zeng LH. Waardenburg syndrome, Hirschsprung megacolon, and Marcus Gunn ptosis. Am J Hum Genet 1987;27:683-6.

6. Lautenschlager NT, Milunsky A, DeStefano A, Farrer L. A novel mutation in the MITF gene causes Waardenburg syndrome type 2. Genet Analysis 1996;13:43-4.

7. Goldberg MF. Waardenburg syndrome with fundus and other anomalies. Arch Ophthalmol 1966;76:797-810.

8. Goodall T, Buffey AJ, Rennie IG, Benson M, Parsons MA, Faulkener MK, MacNeil S. Effect of melanocyte-stimulating hormone on human cultures of choroidal melanocytes, uveal melanoma cells, and retinal epithelial cells. Invest Ophthalmol Vis Sci 1994;35:826-37.

9. Mustardé J. Epicanthal folds and the problem of telecanthus. Trans Ophthalmol Soc UK 1963;83:397-411.

10. Hogan MJ, Alvarado JA, Waddell JE. Histology of the human eye. Philadelphia: Saunders, 1971.

11. Hageman MJ, Delleman JW. Heterogeneity in Waardenburg syndrome. Am J Hum Genet 1977;29:468-85.

12. Liu X, Newton VE, Read AP. Waardenburg syndrome type II: phenotypic findings and diagnostic criteria. Am J Med Genet 1995;55:95-100.

13. Hageman MJ. Waardenburg syndrome in Kenyan Africans. Trop Geogr Med 1978;30:45-55.

14. de Saxe M, Kromberg JG, Jenkins T. Waardenburg syndrome in South Africa. I. An evaluation of the clinical findings in 11 families. S Afr Med J 1984;66:256-61.

15. Feingold M, Robinson MJ, Gellis SS. Waardenburg's syndrome during the first year of life. J Pediatr 1967;71:874-6.

16. Imesch PO, Bindley CD, Khademian Z, Gangnon R, Albert DM, Wallow IHL. Melanocytes and iris color: light microscopic findings. Arch Ophthalmol 1996;114:437-42.

17. Wilkerson CL, Syed NA, Fisher MR, Robinson NL, Wallow IHL, Albert DM. Melanocytes and iris color: electron microscopic findings. Arch Ophthalmol 1996;114:443-7.
18. Eagle RC Jr. Iris pigmentation and pigmented lesions: an ultrastructural study. Trans Am Ophthalmol Soc 1988;88:581-7.

19. Dietrich CE. Zur Feinstruktur der Melanocyten der menschlichen Iris. Graefes Arch Klin Exp Ophthalmol 1972;183:317-33.

20. Weinstein JM, Zweifel TJ, Thompson HS. Congenital Horner syndrome. Arch Ophthalmol 1980;98:1074-8.

21. Laties AM. Ocular melanin and the adrenergic innervation to the eye. Trans Am Ophthalmol Soc 1974;72:560-604.

22. Laties AM, Lerner AB. Iris color and relationship of tyrosinase activity to adrenergic innervation. Nature 1975;255:152-3.

23. Ehinger B, Falck B. Innervation of iridic melanophores. Z Zellforsch 1970;105:538-42.

24. Ringvold A. An electron microscopic study of the iris stroma in monkey and rabbit with particular reference to intercellular contacts and sympathetic innervation of anterior layer cells. Exp Eye Res 1975;20:349-65.

25. Fingerman M. Chromatophores. Physiol Rev 1965;45:196-239.

26. Mukuno K, Witmer R. Innervation of melanocytes in human iris: an electron microscopic study. Graefes Arch Klin Exp Ophthalmol 1977;203:1-8.

27. McCartney ACE, Riordan-Eva P, Howes RC, Spalton DJ. Horner syndrome: an electron microscopic study of a human iris. Br J Ophthalmol 1992;76:746-9.

28. Johnston MC, Noden DM, Hazelton RD, Coulombre JL, Coulombre AJ. Origins of avian ocular and periocular tissues. Exp Eye Res 1979;29:27-43.

29. Spritz RA. Piebaldism, Waardenburg syndrome, and related disorders of melanocyte development. Semin Cutaneous Med Surg 1997;16:15-23.

30. Fisch L. Deafness as part of an hereditary syndrome. J Laryngol Otolaryngol 1959;73:355-83.

31. Beauchamp GR, Knepper PA. Role of the neural crest in anterior segment development and disease. J Pediatr Ophthalmol Strabismus 1984;21:209-14. 